\title{
EXPERIMENTAL STUDY ON STABILITY OF HIGH STRENGTH STEEL LONG COLUMNS WITH BOX-SECTIONS
}

\author{
Lei Gao, Kebin Jiang, Linyue Bai* and Qiang Wang \\ Army Engineering University of PLA, Nanjing 210007, China \\ *(Corresponding author: E-mail: baily016@sina.com)
}

Received: 13 June 2016; Revised: 12 January 2017; Accepted: 25 February 2017

\begin{abstract}
Ten long columns made of high strength steel $18 \mathrm{Mn} 2 \mathrm{CrMoBA}$ (nominal yield stress is $745 \mathrm{MPa}$ ) were employed in axial compression experiments to investigate their overall stability. The columns with thin-walled box-shaped cross-sections were first fabricated into channel shapes followed by welding. The initial geometrical imperfections of the specimens were measured, and the ratio of instability plane initial deflection to the member length was around 1/1000. The finite element model (FEM) which can introduce the influence of geometrical imperfection and residual stress was established. The results of numerical simulation were compared with the experimental results, and the results were in good agreement with the experimental results. Comparisons with Chinese GB50017-2003 specification indicated that the experimental values for the load bearing capacity were greater than that obtained from b-type column curves, but less than a-type column curves. The results were also close to b-type column curves, as defined in the European Eurocode3 steel structure design specification. However, the American ANSI/AISC 360-10 steel structure design specification overestimated the load capacity of this type of long column considered. Therefore, this paper recommends that the design of this type of long column employ the b-type curves specified by the GB50017-2003 or Eurocode3 specifications.
\end{abstract}

Keywords: High strength steel, thin-walled box-shaped cross-sections, axial compression experiment, load bearing capacity, column curve

DOI: $10.18057 /$ IJASC.2017.13.4.5

\section{INTRODUCTION}

With the development of steel production processes, high strength steel has been increasingly used to actual projects. Currently, Japan, the United States, and other countries have engaged in an increasing number of engineering projects employing high strength steel [1-3]. The yield strength of high-strength steel mainly ranges between $460 \mathrm{MPa}$ and $690 \mathrm{MPa}$ [3-6], and some super high strength steel having a yield strength of up to $1100 \mathrm{MPa}$ has been applied to rapid bridge construction applications for the military [7]. In recent years, high-strength steel has been increasingly employed in constructions such as the National Stadium of China [8], the new headquarters of China Central Television [9], Phoenix International Media Center [10], and Electrical Transmission Tower [11]. These buildings primarily employed Q460 high-strength structural steel as the construction material. Utilization of high-strength steel can effectively reduce structural self-weight, increase the usage space of a building, and save cost. In addition, high-strength steels with yield strengths exceeding $700 \mathrm{Mpa}$ have been used as building materials for some movable bridge projects in China [12].

While high-strength steel has been widely applied in engineering projects, no specific design specifications for high-strength steel members have yet been developed in China and abroad. The maximum yield strength of steel considered in the Chinese GB50017-2003 specification is 420 $\mathrm{MPa}$ [13]; thus, research related to high-strength steel stability must be conducted. Currently, investigators in China and abroad have conducted some degree of research in this field. Usami et al. 
[14] conducted stability experimental studies using six columns with box shaped cross-sections made of HT80 high-strength steel with a nominal yield strength of $690 \mathrm{MPa}$, and an empirical formula was proposed based on their experimental results. Rasumussen et al. [15] implemented compression stability experimental studies using eleven columns with welded H-type or box-shaped cross-sections made of BISALLOY80 high-strength steel with a nominal yield strength of $690 \mathrm{MPa}$, and their research results demonstrated that the stability coefficient was apparently improved compared to common steel columns with identical normalized slenderness ratios. Yang et al. [16-18] conducted numerous experiments using short and long columns made of G550 high-strength steel with a yield strength of $550 \mathrm{MPa}$ to study their local and overall buckling properties, and numerical simulations were implemented using ABAQUS finite element software. In China, Shi et al. [19-21] performed experimental studies on the stability performance of domestic Q460 high-strength steel welded columns with box-shaped cross-sections as well as the stability performance related to the strong axis of S690 and S960 welded H-shaped compression columns. The results of their investigation demonstrated that the stability coefficient of high-strength steel columns was apparently greater than those of common steel columns. Li et al. [22] implemented axial compression experiments on seven welded columns with box-shaped cross-sections made of domestic Q460 high-strength middle-thick steel plate, and conducted related finite element analysis. They proposed that the stability coefficient could utilize the b-type curve specified in the GB50017-2003 specification [13].

Numerous research results have demonstrated that the use of high-strength steel in axial compression members decreases the sensitivity of the overall stability to initial imperfections [20], and the decreased ratio of the residual stress to the steel yield strength improved the overall stability coefficient of axial compression members [15]. Therefore, it is essential to ascertain whether or not present steel structural design specifications are applicable to high-strength steels through experimental and theoretical investigations. To this end, the present study experimentally evaluated the stability of ten long columns with thin-walled box-shaped cross-sections made of $18 \mathrm{Mn} 2 \mathrm{CrMoBA}$ high-strength steel with a nominal yield strength of $745 \mathrm{MPa}$, and established a finite element model using finite element software to numerically simulate the experimental process. In addition, the experimental results were utilized to study the applicability of the stability design methods for axial compression members fabricated from $18 \mathrm{Mn} 2 \mathrm{CrMoBA}$ steel respectively given in the GB50017-2003, American ANSI/AISC 360-10 [23], and European Eurocode3 [24] steel structure design specifications.

\section{EXPERIMENTAL OVERVIEW}

\subsection{Specimen Design}

Ten high-strength welded columns made of domestic $18 \mathrm{Mn} 2 \mathrm{CrMoBA}$ steel were designed with box-shaped cross-sections. To prepare the specimens, thin steel plate was firstly cold-formed into channel-shaped members, and then thin-walled box-shaped cross-section columns were formed by butt welding. Compared with the commonly employed fabrication method involving the welding of four plates, this preparation method employed only two welds. To prevent end damage during loading, steel plates of $6 \mathrm{~mm}$ thickness were welded at the two ends of each specimen. Meter and Vernier calipers were employed to measure the geometrical sizes of specimens, and the actual measured sizes are listed in Table 1 . Here, $t$ represents the sectional thickness, $L$ represents the specimen length, $H$ and $B$ represent the sectional height and width of specimens, respectively, and $L o$ represents the space between the rotation centers of the unidirectional cylindrical hinge bearings installed at each end of the specimen, where $L_{0}=L+180 \mathrm{~mm}$, which is discussed in detail in Subsection 2.3. 
Table 1. Measured Dimensions of the Actual Specimens

\begin{tabular}{llllll}
\hline Member number & $t / \mathrm{mm}$ & $L / \mathrm{mm}$ & $H / \mathrm{mm}$ & $B / \mathrm{mm}$ & $\mathrm{Lo} / \mathrm{mm}$ \\
\hline LC1a & 3.34 & 416.1 & 63.06 & 51.20 & 596.1 \\
LC1b & 3.34 & 417.3 & 63.08 & 51.04 & 597.3 \\
LC2a & 3.34 & 617.2 & 62.50 & 50.12 & 797.2 \\
LC2b & 3.42 & 616.0 & 62.34 & 50.26 & 796.0 \\
LC3a & 3.40 & 816.4 & 62.20 & 50.58 & 996.4 \\
LC3b & 3.40 & 815.2 & 62.56 & 50.34 & 995.2 \\
LC4a & 3.28 & 1016.6 & 63.42 & 49.54 & 1196.6 \\
LC4b & 3.30 & 1017.1 & 63.24 & 50.18 & 1197.1 \\
LC5a & 3.36 & 1416.2 & 63.54 & 50.28 & 1596.2 \\
LC5b & 3.22 & 1415.3 & 62.68 & 50.90 & 1595.3 \\
\hline
\end{tabular}

The material properties of the specimens utilized, as previously reported [25], are listed in Table 2, where $t$ represents the plate thickness, $E$ represents the elastic modulus, $f_{y}$ represents the nominal yield strength, $f_{u}$ represents the limited tensile strength, and $f_{y} / f_{u}$ represents the yield ratio.

Table 2. Experimental Results of the Material Properties

\begin{tabular}{llllll}
\hline Specimen number & $t / m m$ & $E / G P a$ & $f_{y} / M P a$ & $f_{u} / M P a$ & $f_{y} / f_{u}$ \\
\hline ts1 & 3.44 & 194.9 & 795 & 935 & 0.8502 \\
ts2 & 3.30 & 196.2 & 791 & 921 & 0.8588 \\
ts3 & 3.34 & 198.6 & 794 & 929 & 0.8546 \\
Average & 3.36 & 196.6 & 793.3 & 928.3 & 0.8545 \\
\hline
\end{tabular}

\subsection{Measurement of the Initial Geometrical Imperfections of Specimens}

Meter and feeler gauges were employed to measure the initial geometrical imperfections of the specimens. The measurements primarily included the initial deformation along the weak axis, i.e., in the instability plane. The front and back planes were respectively measured. Three lines in each plane comprised of two edge lines and one middle line were measured. Four testing points along each line comprised of two end points and two quartile points were tested, and the maximum values of the measured results was treated as the initial geometrical imperfections, which are listed in Table 3, where $\delta$ represents the measured average initial imperfection value. It is observed from Table 3 that the ratio of $\delta / L$ was about $1 / 1000$, which verifies the applicability of using $1 / 1000$ th of the member length specified in the GB50017-2003 specification ${ }^{[13]}$ as the standard value of the initial imperfection.

Table 3. Initial Geometrical Imperfections along the Weak Axis

\begin{tabular}{llll}
\hline Specimen number & $L / m m$ & $\delta / m m$ & $\delta / L$ \\
\hline LC1a & 416.1 & 0.37 & 1124 \\
LC1b & 417.3 & 0.39 & 1070 \\
LC2a & 617.2 & 0.58 & 1064 \\
LC2b & 616.0 & 0.61 & 1009 \\
LC3a & 816.4 & 0.79 & 1033 \\
LC3b & 815.2 & 0.82 & 994 \\
LC4a & 1016.6 & 0.93 & 1093 \\
LC4b & 1017.1 & 1.12 & 908 \\
LC5a & 1416.2 & 2.93 & 483 \\
LC5b & 1415.3 & 1.48 & 956 \\
\hline
\end{tabular}




\subsection{Experimental Equipment}

The experiment utilized a $5000 \mathrm{kN}$ hydraulic testing apparatus for vertical loading. A universal ball hinge was installed at the upper end of the loading equipment, allowing for free rotation. To ensure that the specimen could show buckling features along the weak axis, a unidirectional cylindrical hinge was installed at each end of the specimen, as shown in Figure 1. Meanwhile, to ensure member connection with the cylindrical hinge, a $15 \mathrm{~mm}$ thick loading plate was welded to the end of the specimen. Into the plate was cut a $5 \mathrm{~mm}$ slot wherein the specimen was inserted. The distance between the center of the cylinder and the loading plate was $80 \mathrm{~mm}$; thus, $L_{0}=L+180$ $\mathrm{mm}$, as discussed above. Loading proceeded in discrete steps followed by a pause of $30 \mathrm{~s}$ for measurement reading. For loading levels sufficiently far from the ultimate load capacity, specimens were loaded in increments of 10 to $20 \mathrm{kN}$; however, as the loading approached the ultimate load capacity, specimens were loaded in increments of 1 to $5 \mathrm{kN}$.

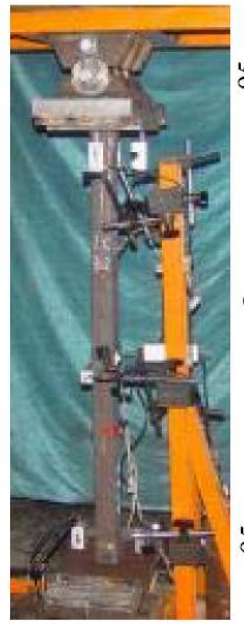

(a) Photograph of on-site loading

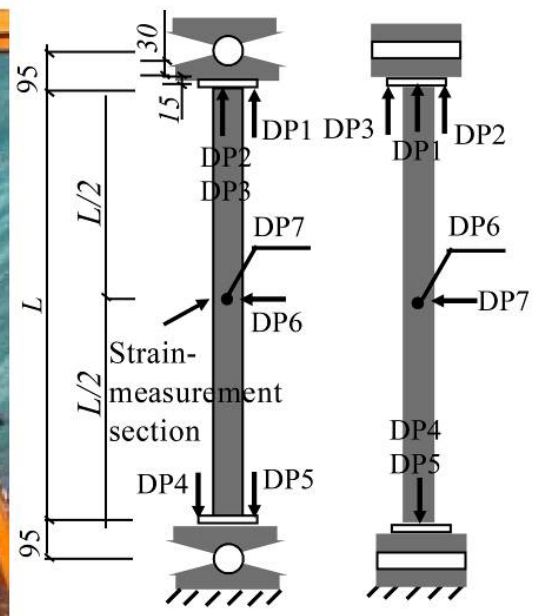

(b) Schematic of loading apparatus

Figure 1. Schematic of the Experimental Loading Apparatus

\section{EXPERIMENTAL RESULTS AND ANALYSIS}

\subsection{Instability Modes and Deformation Analysis}

The status of the failed specimens, as shown in Figure 2, demonstrated a overall instability failure mode. This failure is a type of limit point instability affected by initial imperfections, eccentric loading, and other factors. The specimens exhibited a smaller horizontal deformation during the early stage of loading, and, with a gradually increasing load, the horizontal deformation gradually increased, and presented apparent bending deformation around the weak axis. The tensile strain occurreded on the sectional convex side of the middle span; meanwhile, the compressive strain on the concave side gradually increased until it yielded to a plastic state, although the load could continue increasing. With the development of sectional plasticity and increased bending deformation, specimens could withstand no greater load. Thus, an overall buckling phenomenon became true when the load was reduced. It is observed from Figure 2 that bending deformation became increasingly evident with an increasing specimen slenderness ratio, and instability failure occurred more readily. 


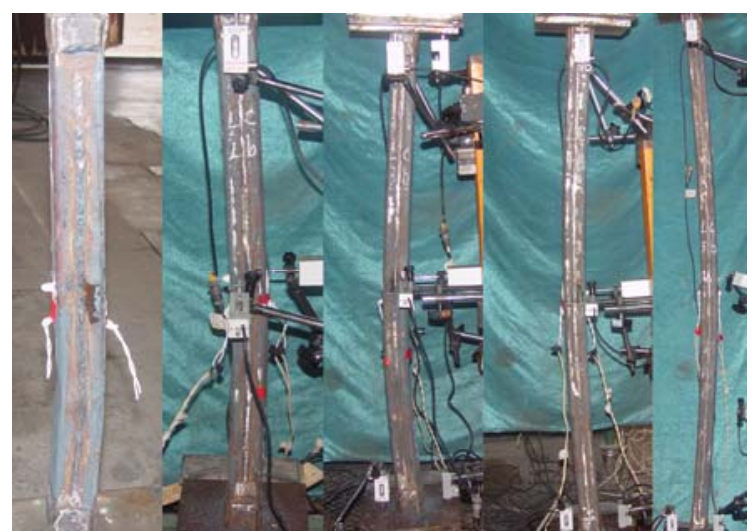

Figure 2. Photographs of Specimen Failure

Figures 3(a) and (b) present the relationships between the testing load and the axial displacement at bearings for specimens $\mathrm{LC} 3 \mathrm{~b}$ and LC4a, respectively. For simplicity, the bearing downside displacement was treated as positive when the displacement meter was compressed; and treated as negative under a tensioned displacement meter. An apparent deformation is observed from the figures at testing point DP1, employed for monitoring rotation at the upper bearing. When the specimens reached their load limit, the upper bearing exhibited a larger rotation, and the displacement meter extended; accordingly, the load and displacement decreased. The experimental results indicate that the upper bearing can represent the end constraint of a simply supported hinge. For the two testing points DP4 and DP5, employed for monitoring rotation at the lower bearing, it is observed from Figure 3(b) that nearly no displacement occurred during the process of loading up to the load limit. This indicates an absence of rotation, and only slight rotation occurred after attaining the load limit of specimens. Therefore, the lower bearing cannot be treated as a hinge bearing, but, rather, as a fixed end constraint over the entire loading process. Accordingly, the specimen constraints were treated as simply supported on one end and a fixed support on the other end. The member length calculation coefficient for the specimen slenderness ratio was 0.7. Specimen LC5a exhibited a maximum initial imperfection. In this case, the reinforcing plate at its lower end fell off during loading, which introduced a large gap between the end and the loading plate, and rotation at the lower hinge during loading; therefore, LC5a could be treated according to a simply supported constraint with a member length coefficient of 1 . The corresponding calculation lengths $L_{j}$ for the specimens are presented in Table 4.

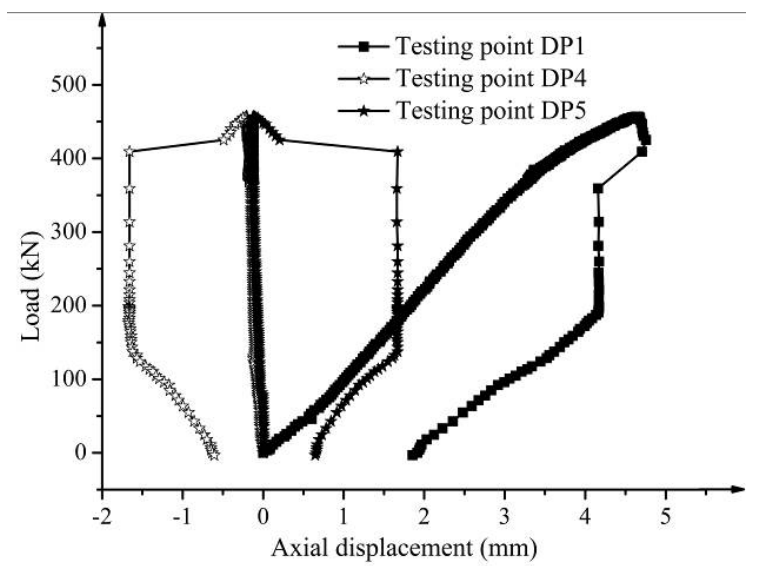

(a) Specimen LC3b

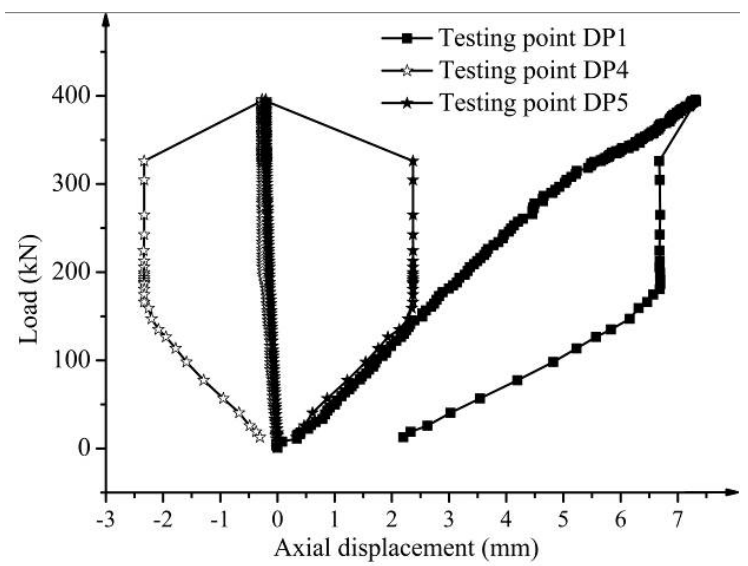

(b) Specimen LC4a

Figure 3. Axial Displacement Curve of the Specimen Bearing 


\subsection{Stability Capacity}

The experimentally determined limit capacities of the specimens are provided in Table 4, where $P_{y}$ represents the capacity, and $P_{y}=A f_{y}$ when the section was fully yielded. $A$ represents the section area of the specimens, $P_{u t}$ represents the stability capacity, $\lambda_{y}$ represents the slenderness ratio along the weak axis of the specimen, and $\lambda_{n}$ represents the normalized slenderness ratio, which, according to the GB50017-2003 specification [13], can be calculated as

$\lambda_{n}=\frac{\lambda_{y}}{\pi} \sqrt{f_{y} / E}$.

The overall stability coefficient $\varphi_{t}$ was determined by

$\varphi_{t}=P_{u t} / P_{y}$.

Table 4. Stability Capacities and Normalized Slenderness Ratios

\begin{tabular}{lllllll}
\hline Specimen number & $L_{j} / \mathrm{mm}$ & $\lambda_{y}$ & $\lambda_{n}$ & $P_{y} / k N$ & $P_{u t} / k N$ & $\varphi_{t}$ \\
\hline LC1a & 417.3 & 20.74 & 0.419 & 570.1 & 559.6 & 0.9816 \\
LC1b & 418.1 & 20.84 & 0.421 & 569.4 & 558.4 & 0.9807 \\
LC2a & 558.0 & 28.33 & 0.573 & 561.4 & 513.5 & 0.9147 \\
LC2b & 557.2 & 28.27 & 0.572 & 573.9 & 515.7 & 0.8986 \\
LC3a & 697.5 & 35.16 & 0.711 & 571.7 & 463.5 & 0.8107 \\
LC3b & 696.6 & 35.26 & 0.713 & 572.4 & 456.8 & 0.7980 \\
LC4a & 837.6 & 42.86 & 0.867 & 553.7 & 395.7 & 0.7146 \\
LC4b & 838.0 & 42.41 & 0.857 & 559.3 & 435.3 & 0.7783 \\
LC5a & 1596.2 & 80.67 & 1.631 & 570.9 & 182.9 & 0.3204 \\
LC5b & 1116.7 & 55.73 & 1.127 & 547.4 & 366.6 & 0.6697 \\
\hline
\end{tabular}

\section{FINITE ELEMENT NUMERICAL SIMULATION}

\subsection{Finite Element Model}

The present research utilized ANSYS [26] software to establish a finite element analysis model, and to conduct numerical simulations. To consider the local buckling and overall relative buckling of the box-shaped cross-section fabricated by welding trough-shaped steel plate, shell elements (shell181), rather than beam elements, were employed. A finite element model based on the elastoplastic large deflection theory of a thin plate was established. Based on the stress-strain curve of the material [25], a multi-linear isotropic strengthening model was selected for the material model. To incorporate the rigid boundary assumption into the model, and to facilitate the application of constraints and loading, two rigid steel plates having a very high elastic modulus were added to the two ends of the member model, and the nodes at the middle of the two end plates were constrained. The established finite element model and constraint modes are presented in Figure 4.

The actual members exhibit a variety of imperfections, which mainly include mechanical imperfections, such as residual stress, and geometrical imperfections such as initial bending, initial member eccentricity, and the initial bending of the plate element. Of these, the numerical simulation should consider the residual stress, the overall initial deflection of a member, and the local imperfections of the plate element. 


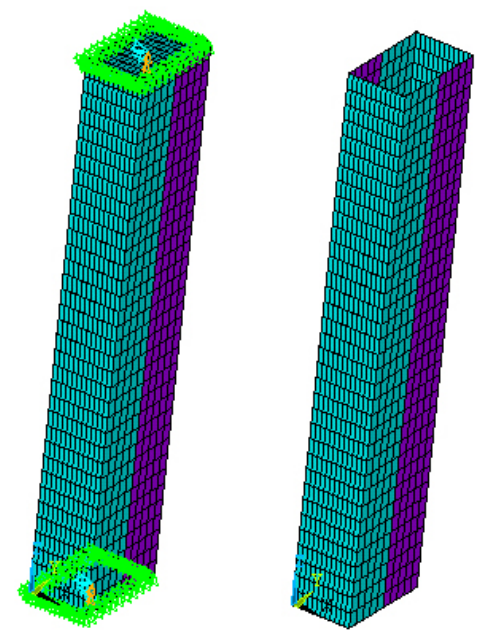

Figure 4. Finite Element Model

\subsubsection{Introduction of geometrical imperfections}

Beginning with the basic model, the locations of nodes were altered according to a semi-sine wave, and the maximum initial deflections listed in Table 3 were applied to the nodes of the model. After alteration of node locations, new elements were generated to establish the overall model.

The consistent imperfection mode method was applied to local defects. An eigenvalue buckling analysis of the structure was conducted to determine the first local buckling mode, which was treated as the reference mode. The obtained reference mode was multiplied by the factor that made the maximum deformation of local buckling equal to the maximum local imperfection amplitude $\Delta_{0}$, and was then applied to the finite element model. The maximum local imperfection amplitude $\Delta_{0}$ was determined by Eq. 3, as proposed by Mateus [27].

$\Delta_{0}=0.1 \beta^{2}$

Here, $\beta=b / t \sqrt{\sigma_{y} / E}$, where $b$ is the width to thickness ratio, and $\sigma_{y}$ is the yield strength. Substituting this expression for $\beta$ into Equation (3) yields

$\Delta_{0} / b=0.1 \times b / t \times \sigma_{y} / E$.

\subsubsection{Introduction of mechanical imperfection}

Shen et al. [28] tested the residual stresses for numerous box-shaped cross-sections made of lower high-strength channel steel, and proposed the residual stress model shown in Figure 5. The researchers proposed that the residual tensile stress $\sigma_{r t}$ be given as $0.832 f_{y}$, and the residual compressive stress $\sigma_{r c}$ be given as $0.0839 f_{y}$. The actual residual stress for box-shaped cross-section members formed by welding cold-rolled trough-shaped steel employed in the present research was a compound stress comprised of cold-bending and welding residual stresses, which are very complicated. To simplify the calculation, the present study employed $0.8 f_{y}$ for $\sigma_{r t}$ and $0.1 f_{y}$ for $\sigma_{r c}$, and the residual stress model employed is shown in Figure 5. 


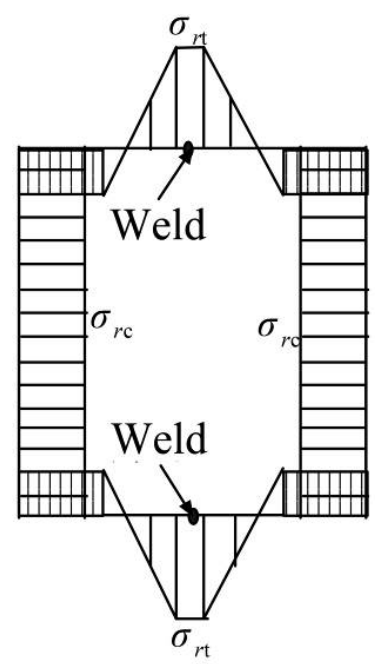

Figure 5. Diagram of the Residual Stress Model

The application of residual stress utilized the method of recording residual stress data [29]. A residual stress data file was prepared for every element in the finite element model, and then the data files were introduced into the model by reading them in the ANSYS software. Every shell181 element has five integration points, so residual stress was applied at the location of integration point of every element.

After constructing the model, the arc-length method was employed for the solution. During the solving process, the applied load, the adopted loading step, and the arc radius were adjusted to ensure tracking of the section where the load-displacement was decreasing. This process was at times repeated to achieve satisfactory results. After completion of the solving process, the universal time processer was used to capture the load-displacement curves of those nodes for which the load limit capacity was attained. A program was prepared for the present study to compute the stability of the modeled steel members using the ANSYS parametric design language [26]. Figure 6 presents the programming flow chart.

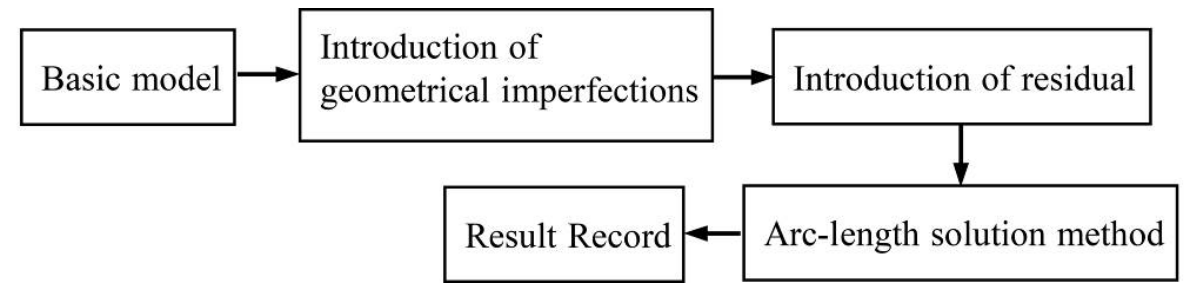

Figure 6. Program Flow Diagram for Computing the Stability of the Modeled Steel Members

\subsection{Numerical Simulation Results}

Table 5 lists the results of all finite element numerical simulation results and their experimental counterparts for comparison. Figure 7 presents a comparison of the load-displacement curves. 
Table 5. Comparison of the Experimental Results and the Results of Finite Element Numerical simulation

\begin{tabular}{llll}
\hline Number & $\mathrm{Pus}_{\mathrm{us}} / \mathrm{Kn}$ & $\mathrm{Put}_{\mathrm{utN}}$ & $\left(\mathrm{Put}_{\mathrm{ut}} \mathrm{Pus}\right) / \mathrm{Put} / \%$ \\
\hline LC1a & 559.6 & 565.7 & 1.07 \\
LC1b & 556.2 & 558.4 & 0.39 \\
LC2a & 488.1 & 513.5 & 4.94 \\
LC2b & 489.5 & 515.7 & 5.08 \\
LC3a & 441.5 & 463.5 & 4.74 \\
LC3b & 442.6 & 456.8 & 3.11 \\
LC4a & 409.8 & 395.7 & -3.56 \\
LC4b & 413.2 & 435.3 & 5.07 \\
LC5a & 193.7 & 182.9 & -5.90 \\
LC5b & 559.6 & 565.7 & 1.07 \\
\hline
\end{tabular}

(a)
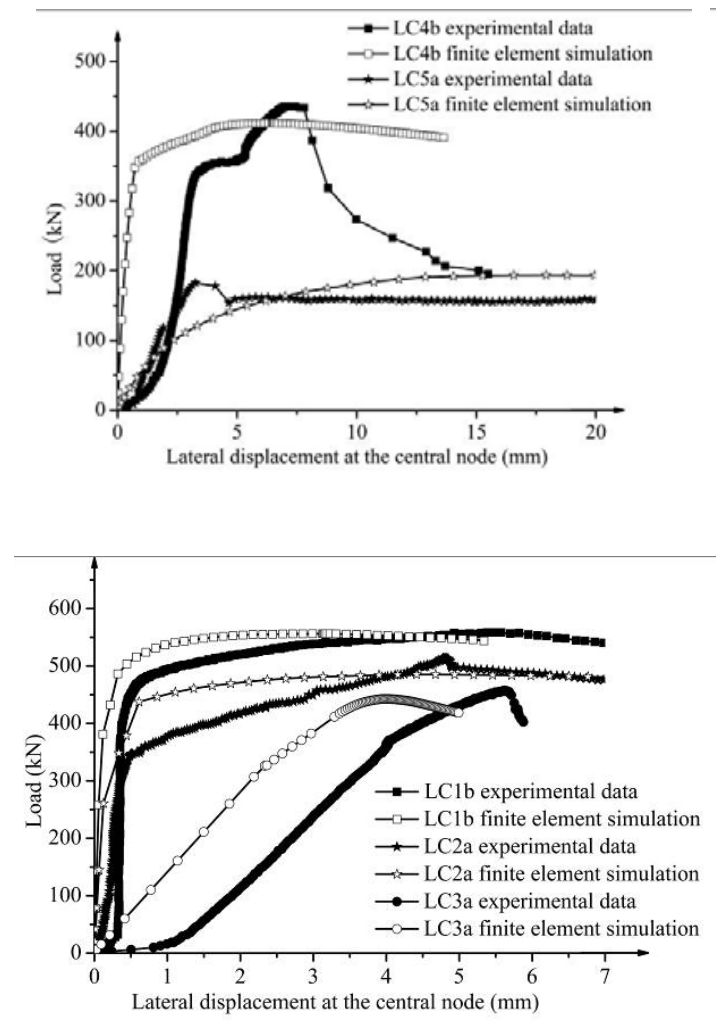

(c)

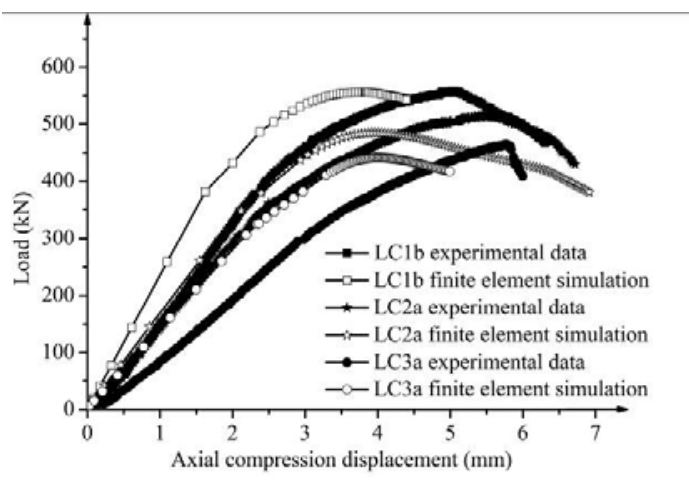

(b)

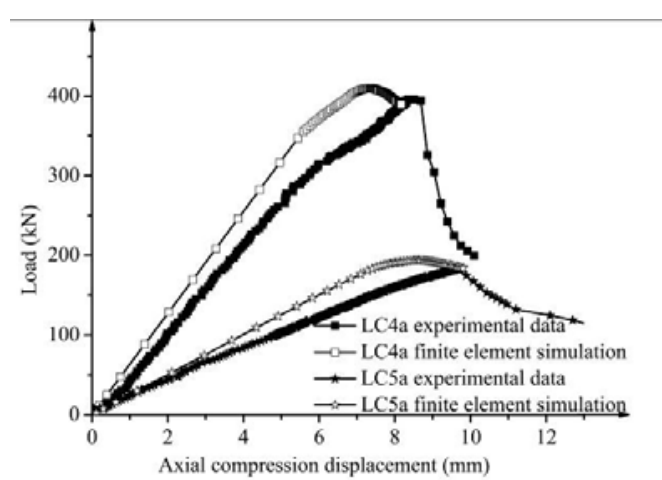

(d)

Figure 7. Comparison of Experimental Load Displacements with those obtained from Finite Element Numerical Simulation

Table 5 shows that, except for specimen LC5, the difference between the finite element numerical simulation results and the experimental results are within 5\%. Figure 7 indicates that the individual load-displacement curves obtained from finite element numerical simulation and experiment exhibit an identical trend, representing good agreement between simulation and experiment. Therefore, the finite element model proposed here accurately simulates the compression process of thin-walled box-shaped cross-section members made of $18 \mathrm{Mn} 2 \mathrm{CrMoBA}$ high-strength steel. 


\section{COMPARISON WITH SPECIFICATIONS}

Figure 8 presents a comparison between the obtained experimental results and those obtained based on the GB 50017-2003 specification [13].

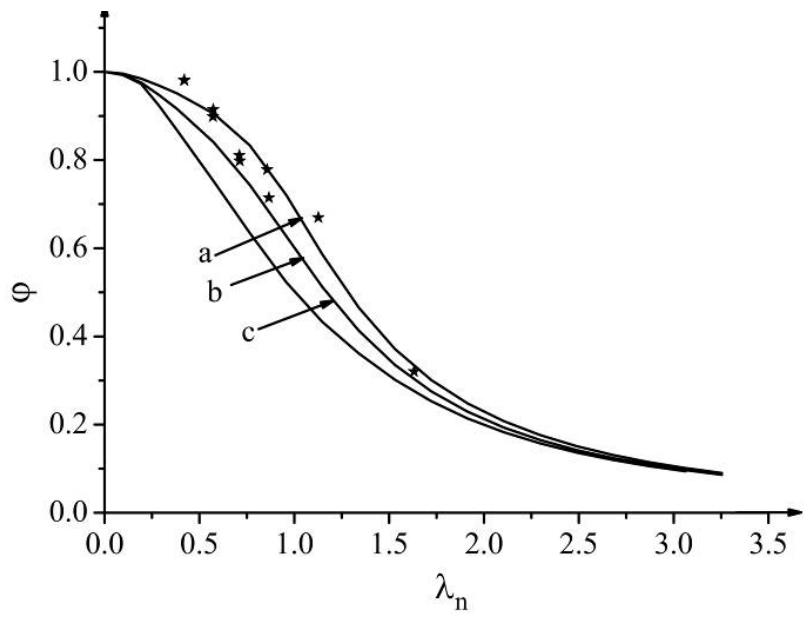

Figure 8. Comparison of Experimental Results and the Results obtained from the Chinese GB 50017-2003 Specification

The bending buckling capacity calculation formula for axial compression members provided by the ANSI/AISC 360-5/360-10 specification [23] is given as follows. The stability capacity $P_{n}$ is given as

$P_{n}=F_{c r} A_{g}$

where $A_{g}$ is the gross sectional area and $F_{c r}$ is the buckling stress. $F_{c r}$ can be calculated by the following formula.

$$
\begin{aligned}
& F_{c r}=\left[0.658^{\frac{f_{y}}{F_{e}}}\right] f_{y}, \frac{K L}{r} \leq 4.71 \sqrt{\frac{E}{f_{y}}} \\
& F_{c r}=0.877 F_{e}, \frac{K L}{r}>4.71 \sqrt{\frac{E}{f_{y}}}
\end{aligned}
$$

Here, the following definitions are applied:

$K$ is the calculation length coefficient of the column;

$R$ is the sectional radius of gyration;

$K L / r$ is the column slenderness ratio $\lambda$;

$F_{e}$ is the elastic buckling critical stress, given as $F_{e}=\pi^{2} E /(K L / r)^{2}$.

When the local buckling of the plate member is not taken into consideration, the normalized slenderness ratio $\lambda_{n}=\frac{\lambda}{\pi} \sqrt{\frac{f_{y}}{E}}$ and the overall stability coefficient $\varphi=P_{n} /\left(f_{y} A_{g}\right)$ are introduced to obtain a column curve calculation formula similar to the GB 50017-2003 specification:

$$
\begin{aligned}
& \varphi=0.658^{\lambda_{n}^{2}}, \lambda_{n} \leq 1.499, \\
& \varphi=0.877 / \lambda_{n}^{2}, \lambda_{n}>1.499 .
\end{aligned}
$$


The Eurocode3 specification [24] classifies member sections into four types according to the degree to which capacity and rotation capability are influenced by local buckling. When the overall buckling is considered as the primary buckling mode, the corresponding capacity calculation formula is given as follows. The stability capacity $N_{b . R d}$ is given as

$$
N_{b, R d}=\frac{\chi A f_{y}}{\gamma_{M 1}},
$$

where $A$ is the gross sectional area of a member and $\chi$ is the overall stability factor. $\chi$ is calculated as

$$
\chi=\frac{1}{\phi+\sqrt{\phi^{2}-\bar{\lambda}^{2}}}, \text { for } \chi \leq 1 .
$$

Here, the following definitions are applied:

$$
\phi=0.5\left[1+\alpha(\bar{\lambda}-0.2)+\bar{\lambda}^{2}\right]
$$

$\bar{\lambda}$ is the normalized slenderness ratio;

$\alpha$ is the imperfection influence factor;

$\gamma_{M 1}$ is the resistance factor for stability design, which is 1 for a building structure.

Every column curve corresponds to a specific value of imperfection influence, and five column curves are specified. A welded box-shaped cross-section member belongs to category III or II of the column curve. When the width-thickness ratio is less than 30 , the member belongs to category III and $\alpha=0.34$, and it belongs to category II and $\alpha=0.49$ when the width-thickness ratio is equal to or greater than 30 .

Figure 9 provides a comparison between the experimental results and calculation results based on Eqs. 8, 9, and 11 for the load bearing capacity of the members considered. Figure 9 indicates that some of the experimental load bearing capacity results were greater, but a few individual data were $3.5 \%$ lower than those obtained by the ANSI/AISC 360-5/360-10 specification. However, the experimental load bearing capacity results were $8.9 \%$ greater than that of the category-b column specified in the Eurocode 3 specification, and were similar to that of the category-b curve of the GB 50017-2003 specification, while exhibiting a 13.2\% difference from that of the category-c curve.

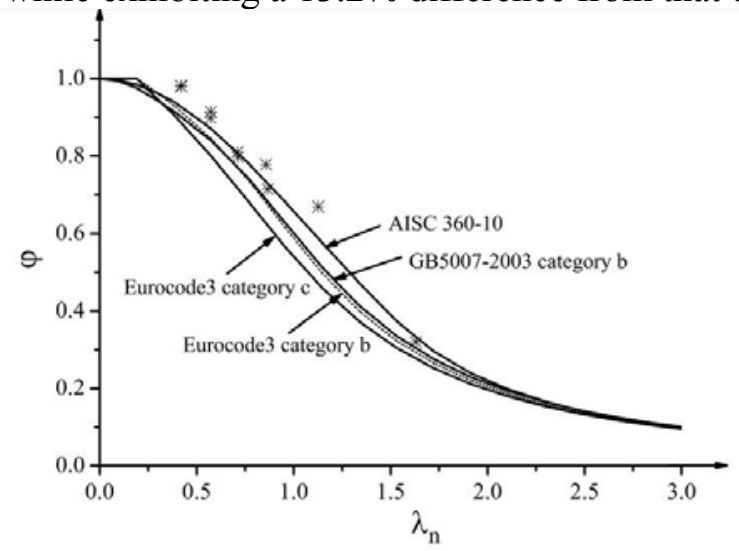

Figure 9. Comparison between the experimental results for the load bearing capacity of the members and those obtained from the European Eurocode3 and American ANSI/AISC 360-10 specifications 


\section{CONCLUSION}

Ten long columns made of high strength steel were employed in axial compression experiments to investigate their overall stability and load bearing capacity under axial compression. The columns had thin-walled box-shaped cross-sections, and were made of $18 \mathrm{Mn} 2 \mathrm{CrMoBA}$ cold-formed steel that was first made into channel shapes followed by butt welding. The results of the study can be summarized as follows.

(1) Measurements of the overall initial imperfections of specimens indicated that the initial deflection of the instability plane can be based on 1/1000th of the member length, as given by the GB 50017-2003 specification for the design process.

(2) Axial compression tests exhibited an overall bending instability mode.

(3) Comparison between the results of experiment and finite element numerical simulation indicated that the proposed finite element model comprehensively captured the influence of initial geometrical imperfection and residual stress on the stability and load bearing capacity of the long columns considered, and could therefore accurately predict these characteristics.

(4) The load bearing capacity attained from specimens was greater than that of the category-b curve of the GB 50017-2003 specification, but lower than that of the category-a curve. The load bearing capacity of specimens was close to that of the category-b curve of the Eurocode 3 specification. Meanwhile, the ANSI/AISC 360-10 specification overestimated the load capacity of the type of steel columns considered.

(5) This research recommends using the category-b curve of the GB 50017-2003 specification and the category-b curve of the Eurocode3 specification for design of long columns with thin-walled box-shaped cross-sections made of $18 \mathrm{Mn} 2 \mathrm{CrMoBA}$ high-strength steel.

\section{ACKNOWLEDGEMENTS}

This research work was financial supported by the Major State Basic Research Development of China (973 Program, Grant No.2014CB046801).

\section{REFERENCE}

[1] Pocock, G., "High Strength Steel Use in Australia, Japan and the US", J. Structural Engineer, 2006, Vol. 84, No. 21, pp. 27-30.

[2] Fukumoto, Y., "New Constructional Steels and Structural Stability", J. Engineering Structures, 1996, Vol. 18, No. 10, pp. 786-791.

[3] Rosier, G.A. and Groll, J.E., "High Strength Quenched and Tempered Steels in Structures", J. Steel Construction, 1987, Vol. 21, No. 3, pp. 2-13.

[4] Cui, W., "Recent Research Advances and Application of High Strength Steel Structures", J. Building Structure, 2011, Vol. 41 (supplement), pp. 958-963.

[5] Shi, G., Ban, H.Y., Shi, Y.J. and Wang, Y.Q., "Overview of Research Progress for High Strength Steel Structures", J. Engineering Mechanics, 2013, Vol. 30, No. 1, pp. 1-13.

[6] Günther, H.P., "Use and Application of High-performance Steels for Steel Structures”, M. Zurich, Switzerland: ETH Honggerberg, 2006.

[7] Li, G.Q., Wang, Y.B., Chen, S.W. and Sun, F.F., "State of the Art on Research of High Strength Structural Steels and Key Issues of Using High Strength Steels in Seismic Structures", J. Journal of Building Structures, 2013, Vol. 34, No. 1, pp. 1-13.

[8] Fan, Z., Liu, X.M., Fan, X.W., Hu, C.Y., et al., 'Design and Research of Large-span Steel Structure for the National Stadium”, Journal of Building Structures, 2007, Vol. 28, No. 2, pp. $1-16$. 
[9] Chen, Z.M., Zhang, Y.L., Peng, M.X. and Zhang, K., "Application of High-strength Steel and Thick Steel Plates to CCTV New Site Building", J. Steel Construction, 2009, Vol. 24, No. 2, pp. 34-38.

[10] Zhou, S.H., Zhu, Z.Y., Qi, W.H., et al., "Structural Design on the Project of Phoenix International Media Center”, J. Building Structure, 2011, Vol. 41, No. 9, pp. 56-62.

[11] Li, Z.L., Liu, H.J., Zhang, D.Y. and Li, M.H., "Application of High-strength Steel Q460 in 1000kv Transmission Towers", J. Power System Technology, 2008, Vol. 32, No. 24, pp. 1-5.

[12] Gou, M.K. and Tao, L., The Application of High Strength Steel ( $\left.\sigma_{s} \geq 700 \mathrm{MPa}\right)$ To Movable Bridge", J. Steel Structure, 2002, Vol. 17, No. 61, pp. 6-9.

[13] GB50017-2003 Code for design of steel structures[S].Beijing: China Planning Press, 2003.

[14] Tsutomu, Usami, Yuhshi, Fukumoto, "Local and Overall Buckling of Welded Box Columns", Journal of Structural Division (ASCE), 1982, Vol. 108, No. ST3, pp. 525-542.

[15] Rasmussen, K.J.R. and Hancock, G.J., "Tests of High Strength Columns", Journal of Constructional Steel Research, 1995, Vol. 34, No. 1, pp. 27-52.

[16] Yang, D. and Hancock, G.J., "Compression Tests of Cold-reduced High Strength Steel Sections, I: stub columns", Journal of Structural Engineering, 2004, Vol. 130, No. 11, pp. 1772-1781.

[17] Yang, D., Hancock, G.J., Ramussen, K.J.R., "Compression Tests of Cold-reduced High Strength Steel Sections, II: Long Columns", Journal of Structural Engineering, 2004, Vol. 130, No. 11, pp. 1782-1789.

[18] Yang, D. and Hancock, G.J., "Numerical Simulation of High-strength Steel Box-shaped Columns Failing in Local and Overall Buckling Modes”, Journal of Structural Engineering, 2006, Vol. 132, No. 4, pp. 541-549.

[19] Shi, G., Lin, C.C., Wang, Y.Q. and Shi, Y.J., "Experimental Study on Local Buckling of High Strength Steel I-section Stub Columns under Axial Compression”, Journal of Building Structures, 2012, Vol. 33, No. 12, pp. 20-30.

[20] Ban, H.Y., Shi, G., Shi, Y.J. and Wang, Y.Q., "Overall Buckling Behavior of Q460 High Strength Steel Welded Box Section Columns under Axial Compression", Journal of Building Structures, 2013, Vol. 34, No. 1, pp. 22-29.

[21] Shi, G., Ban, H.Y., Bijlaard, F.S.K., et al., "Experimental Study and Finite Element Analysis on the Overall Buckling Behavior for Ultra-high Strength Steel Compression Members with End Restraints", China Civil Engineering Journal, 2011, Vol. 44, No. 10, pp. 17-25.

[22] Li, G.Q., Wang, Y.B. and Chen, S.W., "Experimental Study on Ultimate Bearing Capacity of Axially Compression High Strength Steel Columns”, Journal of Building Structures, 2012, Vol. 33, No. 3, pp. 8-14.

[23] ANSI/AISC 360-10.Specification for Structural Steel Buildings, Chicago : American Institute of Steel, Construction, 2010.

[24] BS EN 1993-1-1 Eurocode 3 : Design of Steel Structures,Part 1-1:General Rules and Rules for Buildings, Brussels: European Committee for Standardization, 2005.

[25] Gao, L., Sun, H.C., Jin, F.N., et al., "Load-carrying Capacity of High-strength Steel Box-sections I: Stub columns”, Journal of Constructional Steel Research, 2009, Vol. 65, No. 4, pp. 918-924.

[26] Wang, J.L., ANSYS12.0 Finite Element Analysis and Example, Beijing:China Machine Press, 2010. (in Chinese).

[27] Antonio, F., Matens, Joel A. Witz, "A Parameter Study of the Post-buckling Behaviour of Steel Plate, Engineering Structure, 2001, Vol. 23, pp. 172-185.

[28] Shen, Z.Y. and Zhang, Q.L., "Post-Buckling Ultimate Load-Carrying of Compressed Square-Tube Steel Column”, Journal of Civil Engineering, 1991, Vol. 24, No. 3, pp. 15-26.

[29] Deena, K. Dinno, "Strength and Ductility of Steel Members based on Post-yield Stability and Collapse Behaviour", Doctor of Philosophy, Canada: Department of Civil Engineering University of Toronto, 2002. 